\title{
Electrical Conductivity Study of Pvc: Pmma Polymer Blend Thin Film Thermoelectret Using Al, Cu And Ag Electrodes
}

\author{
Gyanmala Saxena ${ }^{1}$, Dr. Y. K. Kulshrestha ${ }^{2}$, Dr. J. K. Upadhyay ${ }^{3}$ \\ '(Lecturer Physics, G.G.I.C.Orai, India) \\ ${ }^{2}$ (Retd.H.O.D. Physics, D.V.P.G.College,Orai / Bundelkhand University Jhansi, India) \\ ${ }^{3}$ (Retd.H.O.D. Physics, B.B.College,Jhansi / Bundelkhand University Jhansi, India)
}

\begin{abstract}
The goal of this study is to determine the electrical conductivity of the PVC: PMMA polymer blends in thin film thermoelectret form using $\mathrm{Al}, \mathrm{Cu}$ and $\mathrm{Ag}$ as electrode material at various temperatures in the range $323 \mathrm{~K}$ to $363 \mathrm{~K}$. Al-film-Al, Al-film-Cu, and Al-film-Ag structure has been investigated for presenting the results in the form of I-V characteristics. Analysis on various results has been made by interpretation of Poole-Frenkle , Fowler-Nordheim, Schottky ln J vs T plots, and Richardson plots, which suggests that Schottky Rechardson mechanism are primarily responsible for the observed conclusions.
\end{abstract}

Keywords: Electrical Conductivity, Electrode material, Polymer, PVC: PMMA Polymer Blend, Schottky Rechardson Mechanism,

\section{Introduction}

Polymer composites have steadily gained growing importance during past decade. A good amount of work has been reported on the conduction mechanism in polymeric materials. The electrical conduction in polymer films has gained much importance due to discovery of memory phenomenon and has wide applications now-a-days in thin film devices (Mead 1961). In recent years, because of the need for electrostatic charges dissipation, electromagnetic shielding etc., new polymers with electrical conductivity have been formulated.

The unique properties of amorphous semiconductors and insulators and the advantages of producing them by means of a thin film process, which does not limit their size and makes them adaptable to integration with other solid state technologies, have made these materials the base for new area of science and technology. In the past two decades, thin film systems of sandwich type of metal - Insulator-Metal (MIM) have been used to a significant extent in practical situations, as both passive and active elements.

PVC as proton donor and PMMA as proton acceptor are selected for the present study. The choice of these polymers thus takes into account the donor acceptor capabilities. In present study, D.C. conduction of donor-acceptor mixed polymers was measured to identify the mechanism of electrical conduction. It is shown how the I-V data of the sample can be used to arrive at a possible conclusion. Results have been discussed in the light of different mechanisms [1, 2, 3]

\section{1 film preparation}

\section{Experimental Details}

By isothermal evaporation method, structurally reproducible, coherent uniform smooth films free from pinholes can be grown. Excellent reproducibility and simplicity of preparation have prompted a large section of workers to adopt solution grown polymer films for different investigation. But in choosing this method, for preparing polymer films in present work following steps are necessary to follow.

1. A proper substrate is a fundamental requirement in film preparation. A good substrate should not react with the polymer, solvent and surroundings. Its surface must be smooth, uniform, clean and clear and also be easily washable for repeated use. Since last decade glass is used by the researchers but in present investigation four types of substrate are used for making polymer blend films. These are,

1. Thin glass plates (cover slips)

2. Aluminum sheet/foil

3. Silver sheet/foil (All of uniform surface with no impurity)

4. Copper sheet/foil

For using silver, aluminum and copper foils/sheet the reason is that, in further steps of study these materials are used as electrodes. Making film on glass sheet is the step to follow previous workers. And by using both types of substrate glass and metal we get two ways for carrying out our study.

2. For cleaning all types of substrate layers washed in the tap water and then boiled in distilled water. For avoiding oxide formation on metal foils they were dried properly at a fast rate

3. To prepare the best quality smooth and free from pin holes film a solvent of high boiling point should be used. For this reason polymer blends were prepared by simply dissolving the PVC and PMMA in different 
weight proportions (5:5,6:4,7:3,8:2,) in a common solvent Cyclohexanone (B.P. $155^{0}$ ) (Supplied from T.S. corporation Mumbai). The solution was continuously stirred for $120 \mathrm{~min}$ and heated at $50^{\circ} \mathrm{C}$ to obtain a homogeneous solution. Then solution was kept at room temperature for 12 hours with time to time stirring. After stirring solution for specific hours with a glass stirrer the films were prepared by pouring the solution on a clean substrate plate (Glass, $\mathrm{Al}, \mathrm{Cu}$, and $\mathrm{Ag}$ ) floating on a mercury pool. A great care was taken to avoid air bubbles during the setting of polymer solution on the substrate plate. This substrate plate in mercury pool was placed in a dust free chamber at a constant temperature to remove all the traces of solvent. After complete evaporation of solvent, films can be used for different studies. [2,4]

\section{2 thickness measurement}

In present study for measuring the thickness of the film Micrometer screw gauge and an electronic thickness measurement gauge (having accuracy up to $0.1 \mu \mathrm{m}$ ) have been used. (Thickness of the sample $=60 \mu \mathrm{m}$ )

\section{3 conductivity measurements}

The films were sandwiched between two metal electrodes (There are three types of metal electrode combinations; they are $\mathrm{Al}-\mathrm{Al}, \mathrm{Al}-\mathrm{Cu}$ and $\mathrm{Al}-\mathrm{Ag}$ ). The procedure adopted was as follows first the sample was allowed to attain the desired temperature in a thermostat after which the field was applied to it by the help of a stabilized power supply. It is observed that the current is transient in the beginning. It decreases rapidly first, slowly afterwards and becomes steady after a lapse of time which may vary from a few minutes to several hours depending upon the field and temperature of investigation. The films subjected to high fields and high temperatures quickly attain the steady value of current and vice-versa. Observations were taken only when the current reached to its steady value. A fresh sample was used for each set of observations. [5, 6]

\section{Results and discussion}

$\operatorname{Ln}(\mathrm{I})$ vs. $\ln (\mathrm{V})$ plots of PVC : PMMA blend thin films of various ratios at different temperatures $(323 \mathrm{~K}, 333 \mathrm{~K}$, $343 \mathrm{~K}, 353 \mathrm{~K}$ and $363 \mathrm{~K}$ ) using different types of electrode configurations $\mathrm{Al}-\mathrm{Al}, \mathrm{Al}-\mathrm{Ag}$ and $\mathrm{Al}-\mathrm{Cu}$ are shown in Fig. 1 to Fig. 4.

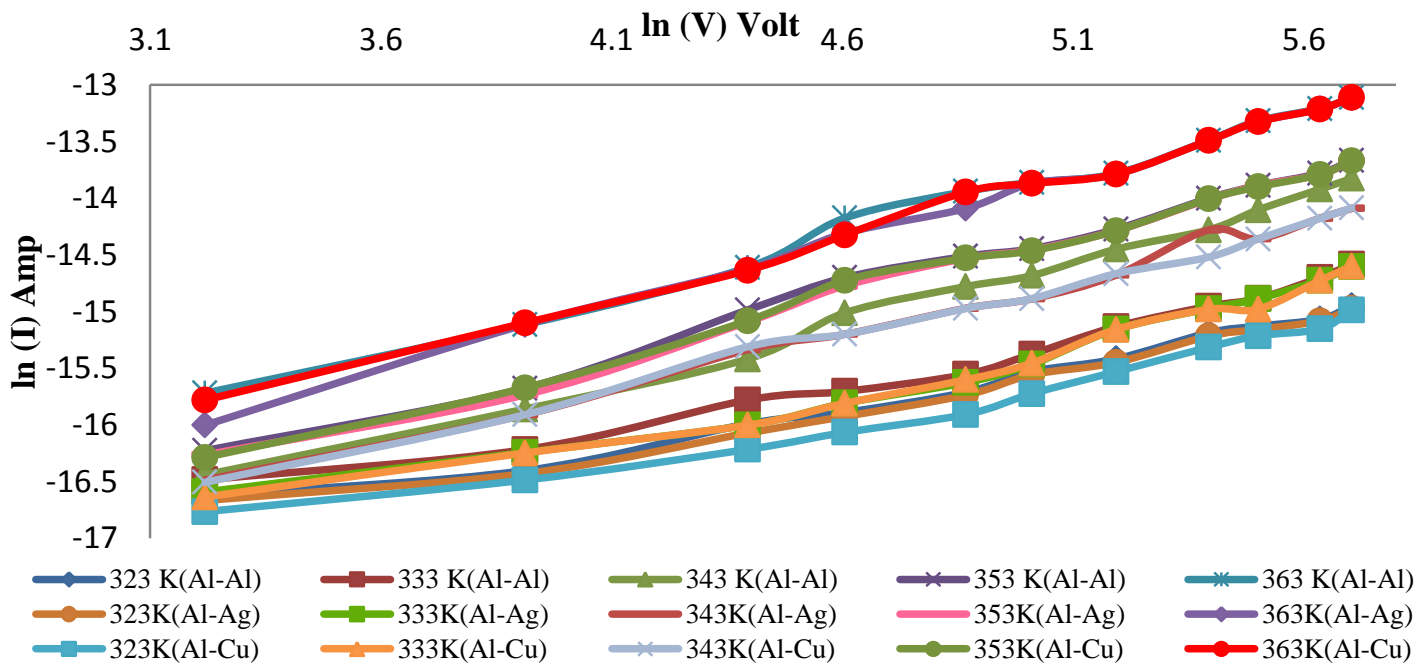

Figure 1. $\ln (\mathrm{I})$ vs. $\ln (\mathrm{V})$ characteristics (PVC: $\mathrm{PMMA} ; 5: 5)$ ( $\mathrm{Al}-\mathrm{Al} ; \mathrm{Al}-\mathrm{Ag} ; \mathrm{Al}-\mathrm{Cu}$ electrode combinations) 


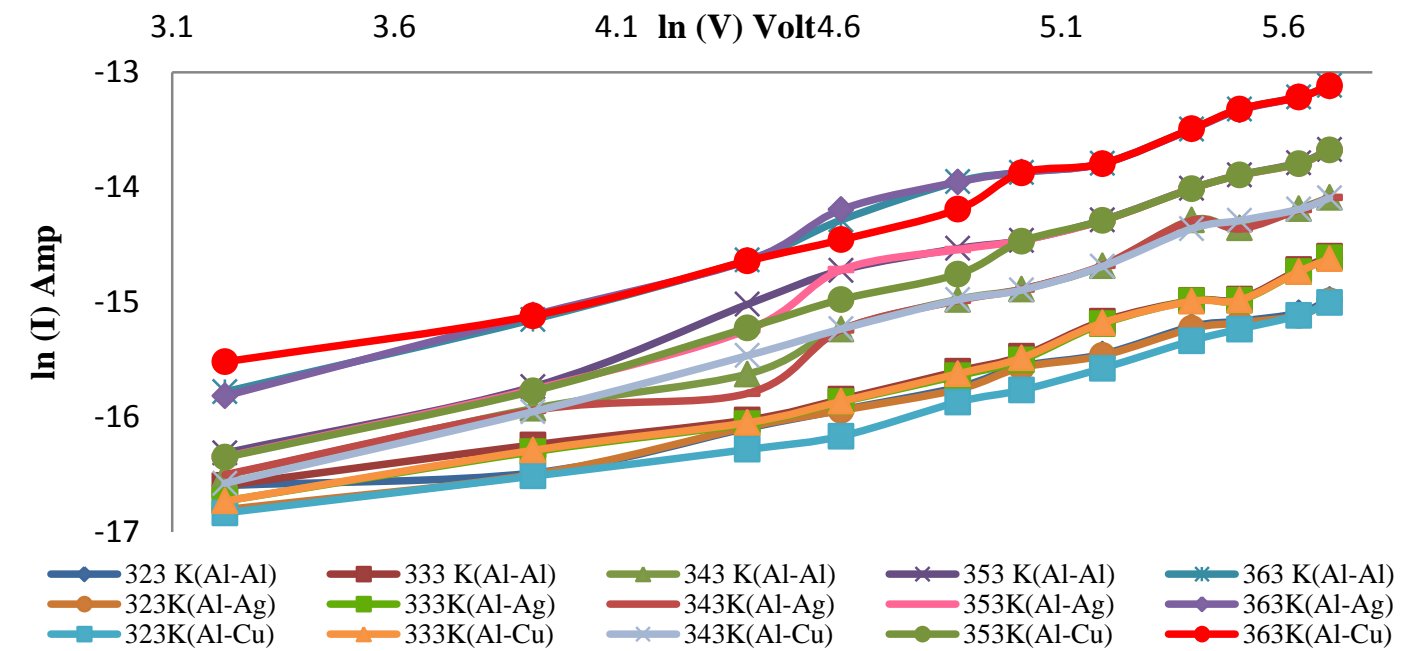

Figure 2. $\ln (\mathrm{I})$ vs. $\ln (\mathrm{V})$ characteristics (PVC: PMMA; 6:4) (Al-Al; Al-Ag; $\mathrm{Al}-\mathrm{Cu}$ electrode combinations)
3.1
3.6
$4.1 \ln (\mathbf{V})$ Volt 4.6
5.1
5.6

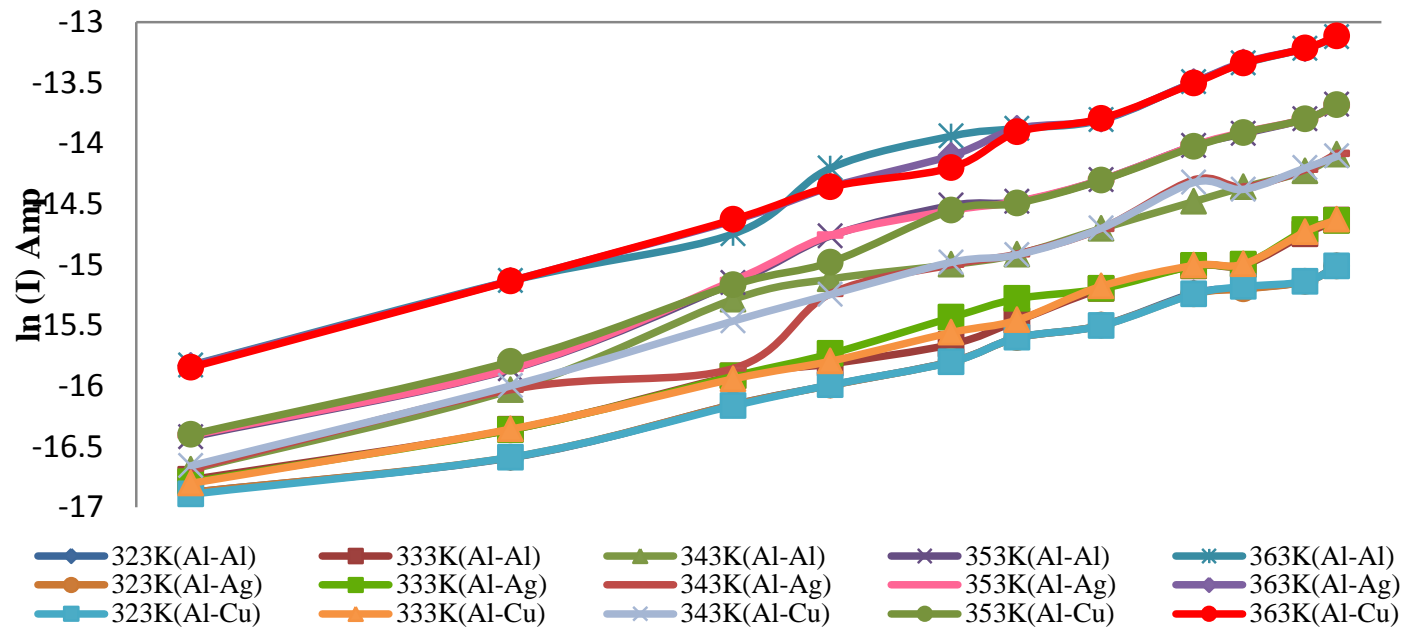

Figure 3. $\ln (\mathrm{I}) \mathrm{vs} . \ln (\mathrm{V})$ characteristics (PVC: PMMA; 7:3) (Al-Al; $\mathrm{Al}-\mathrm{Ag} ; \mathrm{Al}-\mathrm{Cu}$ electrode combinations)

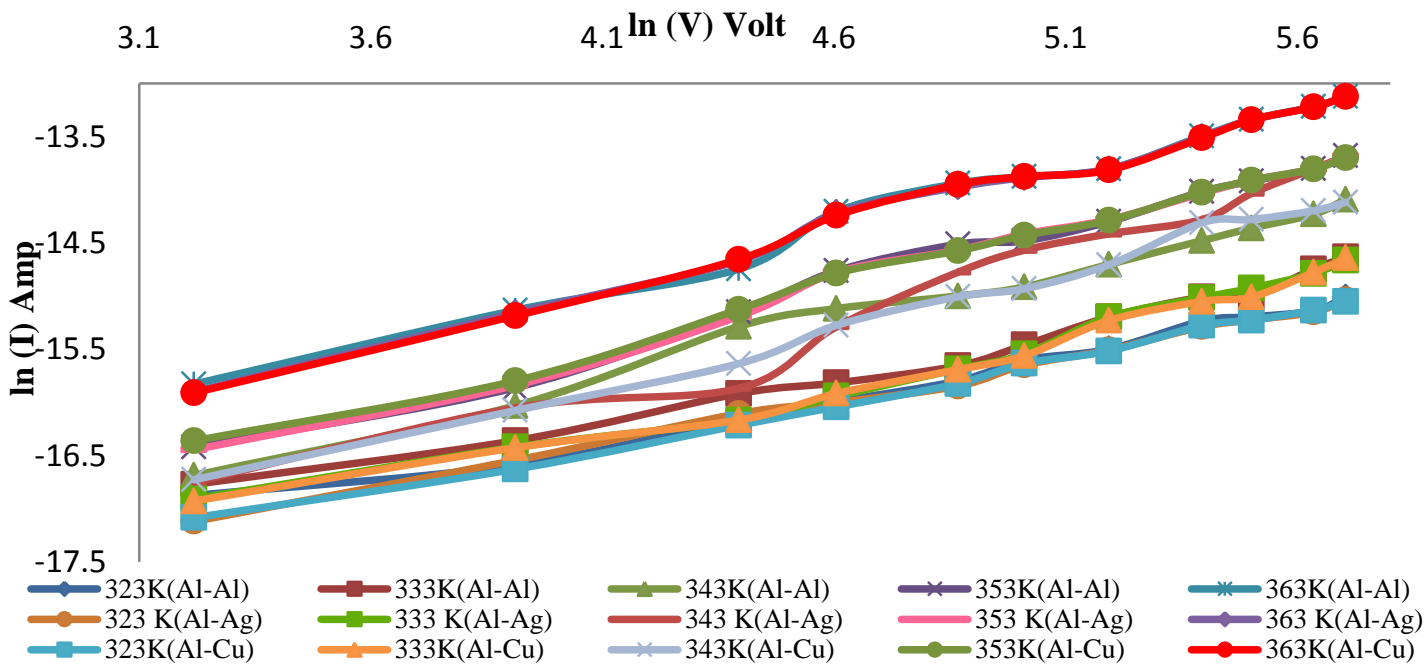

Figure 4. $\ln (\mathrm{I}) \mathrm{vs} \cdot \ln (\mathrm{V})$ characteristics (PVC: PMMA; 8:2) (Al-Al; Al-Ag; Al-Cu electrode combinations)

The current increases non-linearly with applied voltage and does not follow a power law, $\mathrm{I}=\mathrm{kV}^{\mathrm{m}}$, where $\mathrm{k}$ and $\mathrm{m}$ are constants. The possibility of Ohmic conduction as well as space charge limited conduction is ruled out from the observed behavior of I-V characteristics. This is also evident from the fact that ohms law 
follows from the free electron model of a metal. The free electron in a metal under goes frequent collisions, which are not billiard balls collisions with other electrons, but represent the scattering of electron waves by irregularities in the crystal structure, both defects such as impurity atoms and also atoms temporarily out of placed as they vibrate (the atom of a perfect crystal lattice do not scatter free electron wave except under certain specific circumstances). In the present case the constituents of blends are itself insulators and blends almost amorphous, giving wide scope for irregularities in the structure and so ruling out Ohmic conduction.

Regarding space charge limited conduction; it follows that electrical conduction may occur through the movement of either electrons or ions. The polymeric subgroup falls at low conductivity end. In most polymeric material, it is very difficult to observe an electronic conductivity at all and what conductivity there is usually depends upon movement of adventitious ions. Naturally with so feeble charge carrier density, space charge limited conduction seems a remote possibility

From $\ln (\mathrm{I})$ vs $\ln (\mathrm{V})$ curves we observed that the increment in current is approximately the same for whole range of temperatures. The nature of thermo-gram is similar for all temperatures. The magnitude of the current at fixed temperature has been found lower in dissimilar electrode combination ( $\mathrm{Al}-\mathrm{Cu}$ and $\mathrm{Al}-\mathrm{Ag}$ ) then similar electrode system $\mathrm{Al}-\mathrm{Al}$. The dissimilar electrode configuration ( $\mathrm{Al}-\mathrm{Cu}$ and $\mathrm{Al}-\mathrm{Ag}$ ) is made by taking $\mathrm{Cu}$ and $\mathrm{Ag}$ as upper electrode while the lower electrode is of $\mathrm{Al}$ metal in each combination. The analytical and probable discussion of mechanism of conduction in present case has been observed by the virtue of following plots related to various possible mechanisms. $[3,6]$

\subsection{Poole Frankel plots}

The Poole-Frenkel mechanism predicts a field dependent conductivity $(\sigma)$ as, $\sigma=\sigma_{0} \exp \left[\frac{\beta_{\mathrm{PF}} \mathrm{E}^{1 / 2}}{2 \mathrm{KT}}\right]$ or $\ln \sigma=\ln \sigma_{0}+\frac{\beta_{\mathrm{PF}} \mathrm{E}^{1 / 2}}{2 \mathrm{KT}}$

Where, $\beta_{\mathrm{PF}}=\left(\frac{\mathrm{eE}}{\pi \varepsilon_{\mathrm{r}} \varepsilon_{0}}\right)^{1 / 2}$ is the Poole-Frenkel coefficient and all other symbols have their usual meanings. [7, 8]

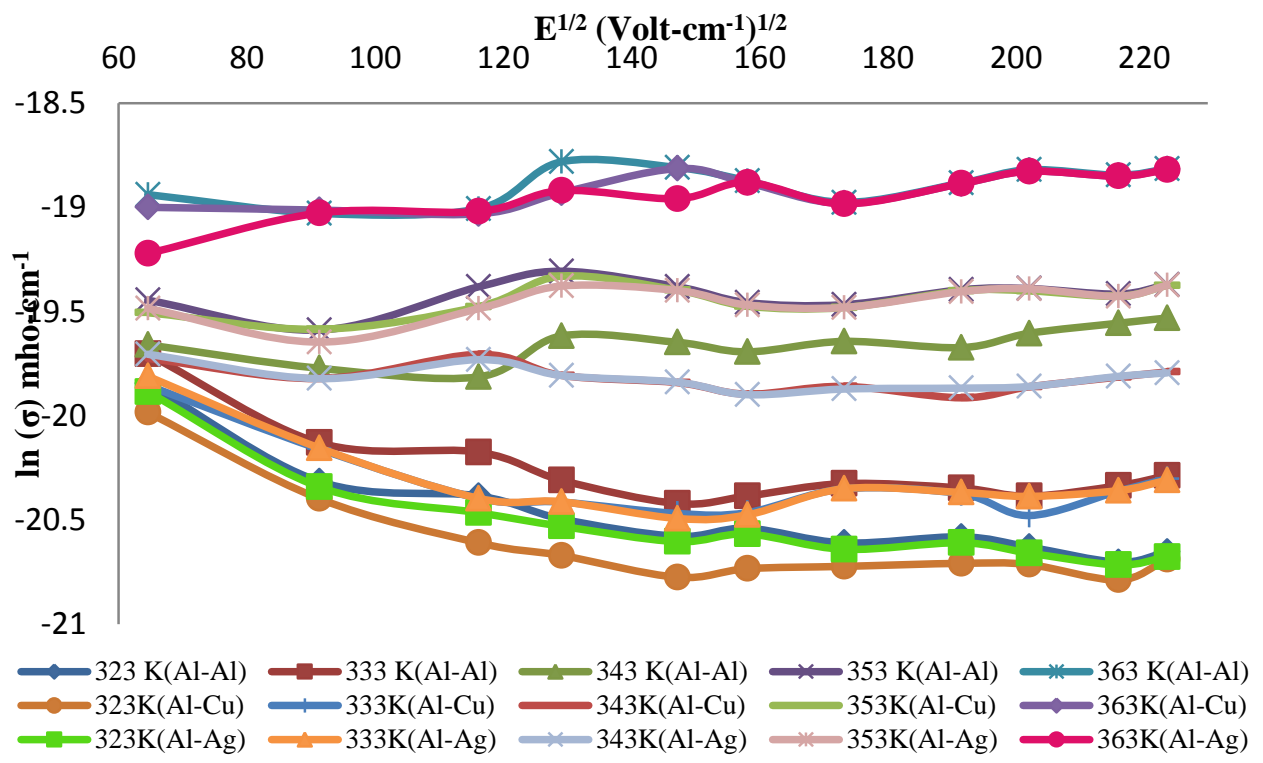

Figure 5. Poole-Frenkel plots (PVC: PMMA; 5:5) (Al-Al; Al-Ag; $\mathrm{Al}-\mathrm{Cu}$ electrode combinations) 


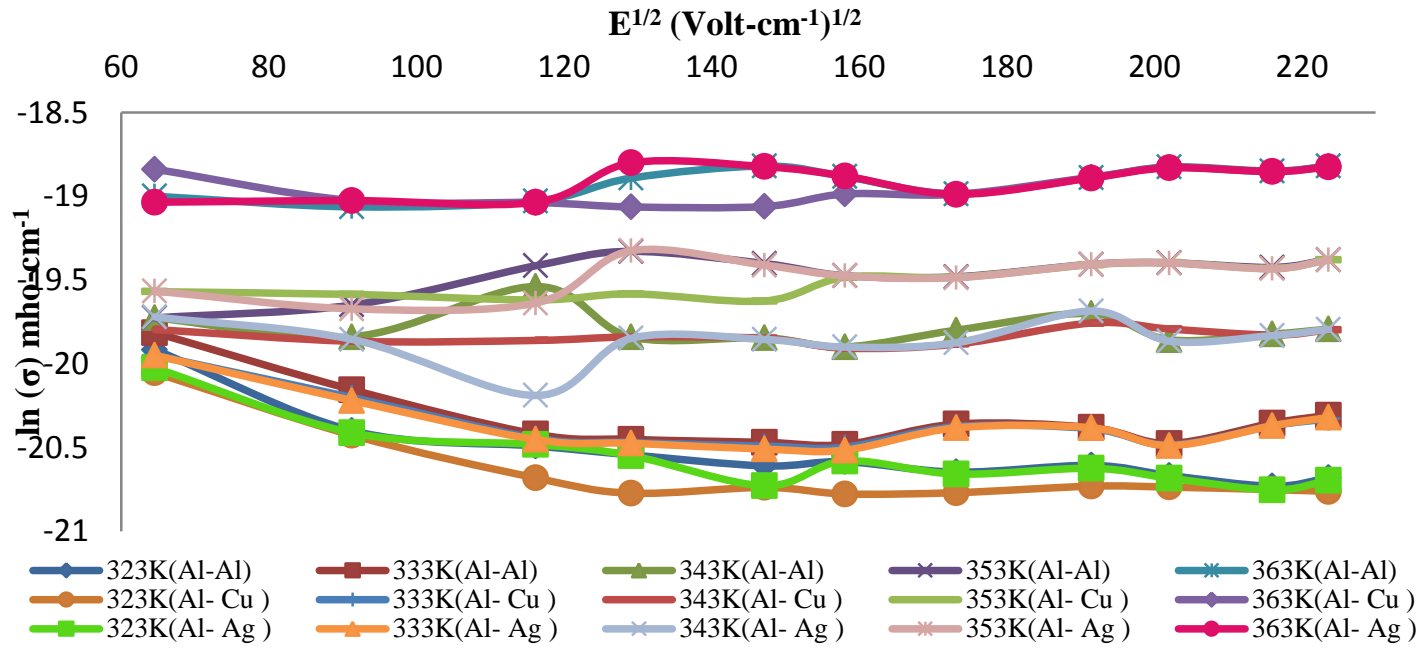

Figure 6. Poole-Frenkel plots (PVC: PMMA; 6:4) (Al-Al; Al-Ag; Al-Cu electrode combinations)

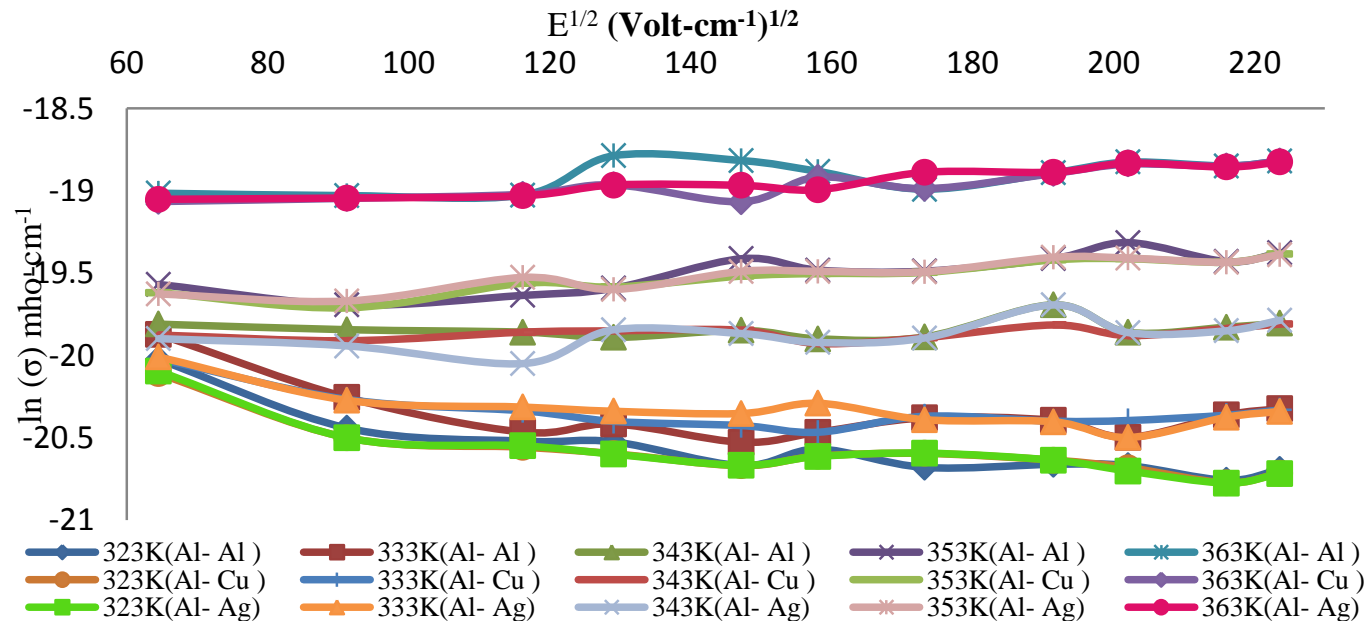

Figure 7. Poole-Frenkel plots (PVC: PMMA; 7:3) (Al-Al; Al-Ag; Al-Cu electrode combinations)

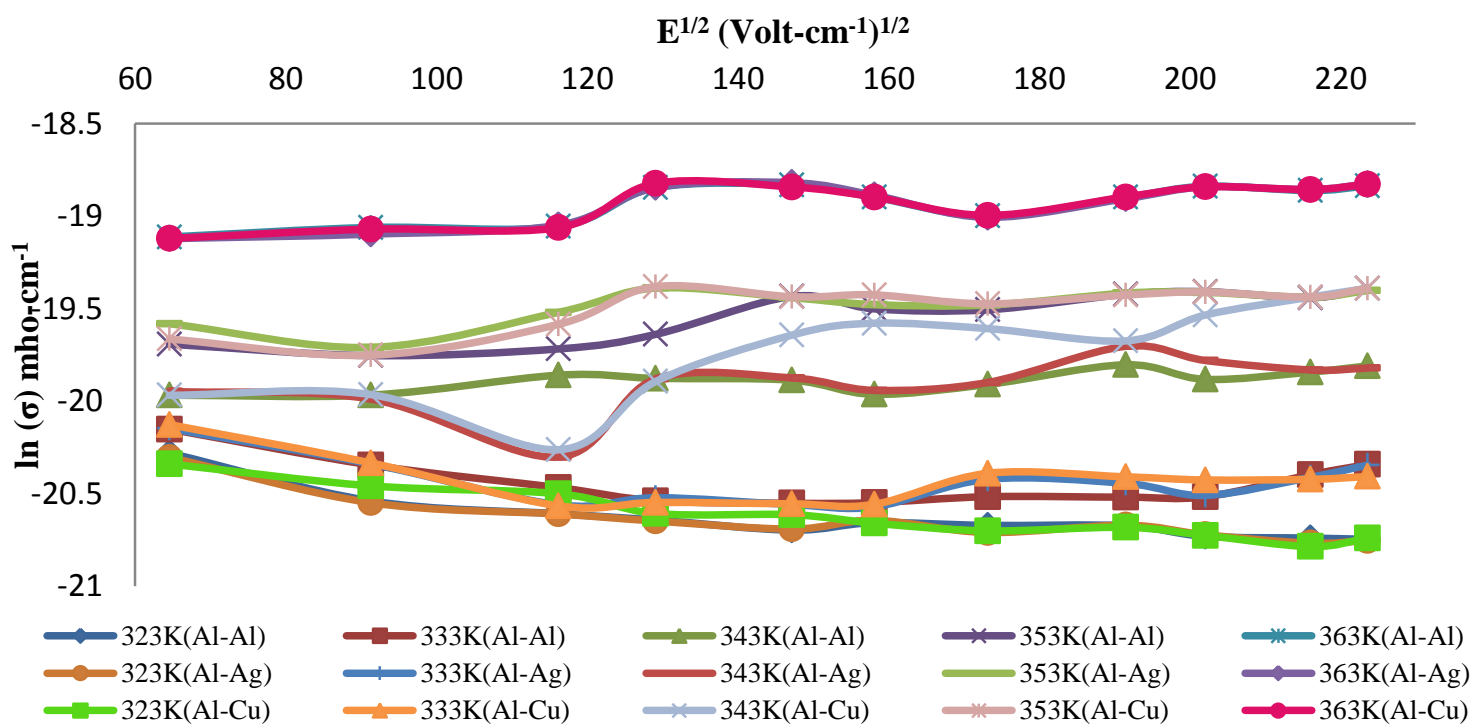

Figure 8. Poole-Frenkel plots (PVC: PMMA; 8:2) (Al-Al; $\mathrm{Al}-\mathrm{Ag} ; \mathrm{Al}-\mathrm{Cu}$ electrode combinations)

It is clear that the Poole-Frankel mechanism is characterized by the linearity of $\ln \sigma$ vs $E^{1 / 2}$ plots i.e. Poole-Frankel plots predicted by equation (1) are linear with a positive slope. In the present case of PVC:PMMA blend films, it can be inferred from the Poole-Frankel plots in Fig.5 to Fig.8, that this mechanism 
does not contribute significantly due to the conduction as $\ln \sigma$ does not show appreciable dependence on $\mathrm{E}^{1 / 2}$ axis indicating absence of PF mechanism.

\subsection{Fowler-Nordheim plots}

More functional empirical form of the Fowler Nordheim eqation is,

$\mathrm{J}=\mathrm{AV}^{2} \exp \left(-\frac{\emptyset}{\mathrm{V}}\right)$ or $\ln \mathrm{J} / \mathrm{V}^{2}=\ln \mathrm{A}-\frac{\emptyset}{\mathrm{V}}$

Where, $\emptyset=$ work function of cathode [8]

$1000 / \mathrm{V}^{(\text {Volt })^{-1}}$
0
10
20
30
40

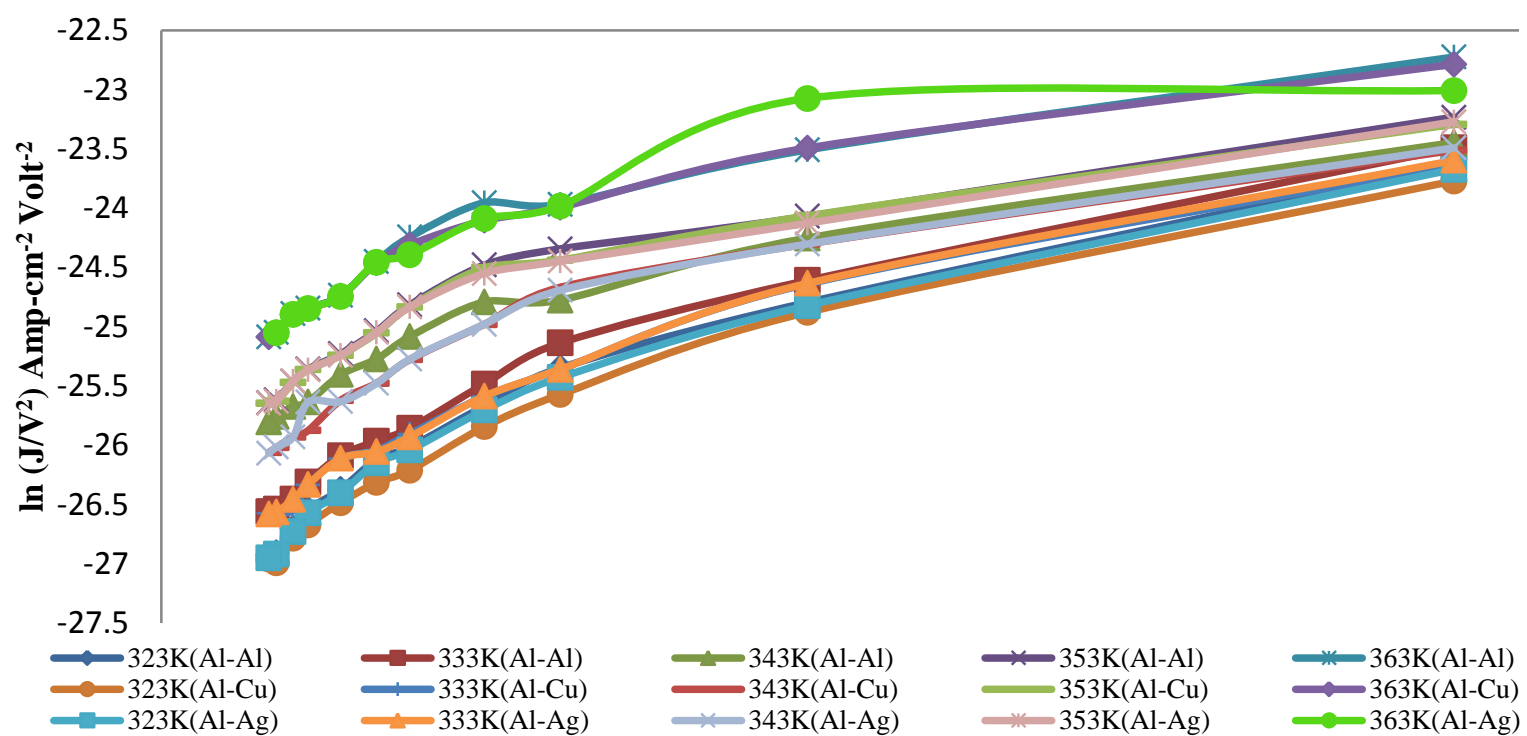

Figure 9. Fowler-Nordheim plots (PVC: PMMA; 5:5) (Al-Al; $\mathrm{Al}-\mathrm{Ag}$; $\mathrm{Al}-\mathrm{Cu}$ electrode combinations)

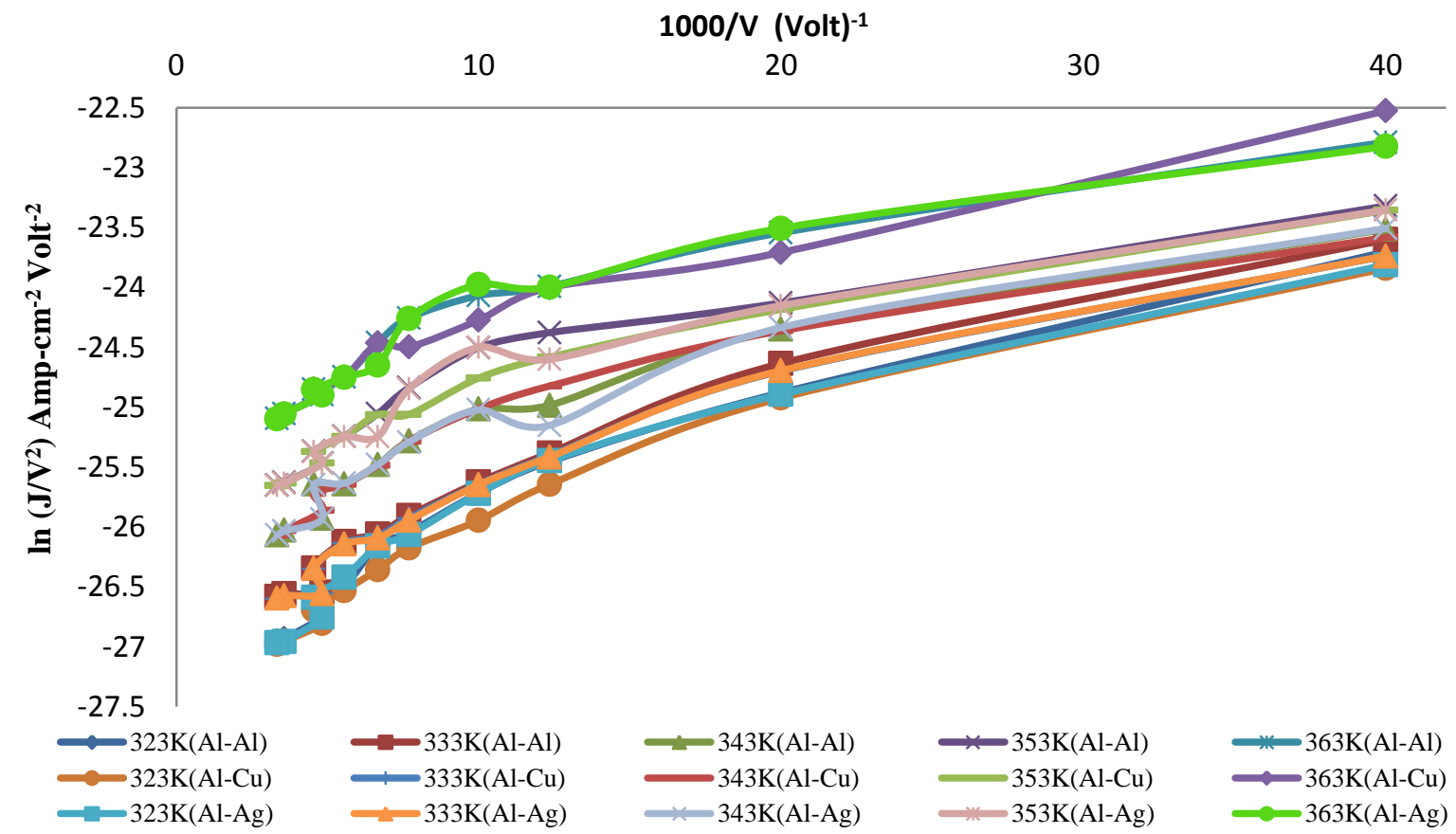

Figure 10. Fowler-Nordheim plots (PVC: PMMA; 6:4) (Al-Al; Al-Ag; $\mathrm{Al}-\mathrm{Cu}$ electrode combinations) 


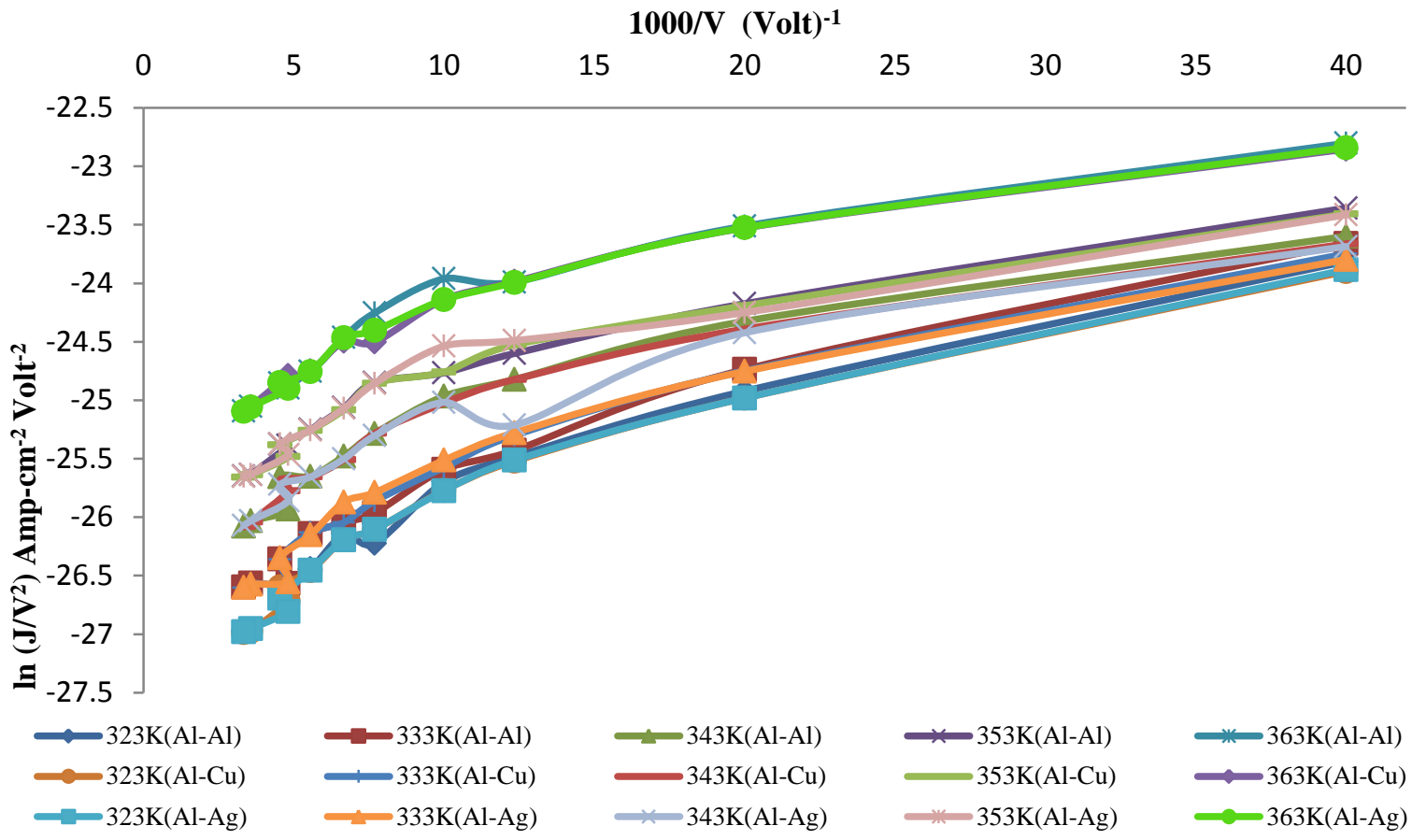

Figure 11. Fowler-Nordheim plots (PVC: PMMA; 7:3) (Al-Al; $\mathrm{Al}-\mathrm{Ag} ; \mathrm{Al}-\mathrm{Cu}$ electrode combinations)

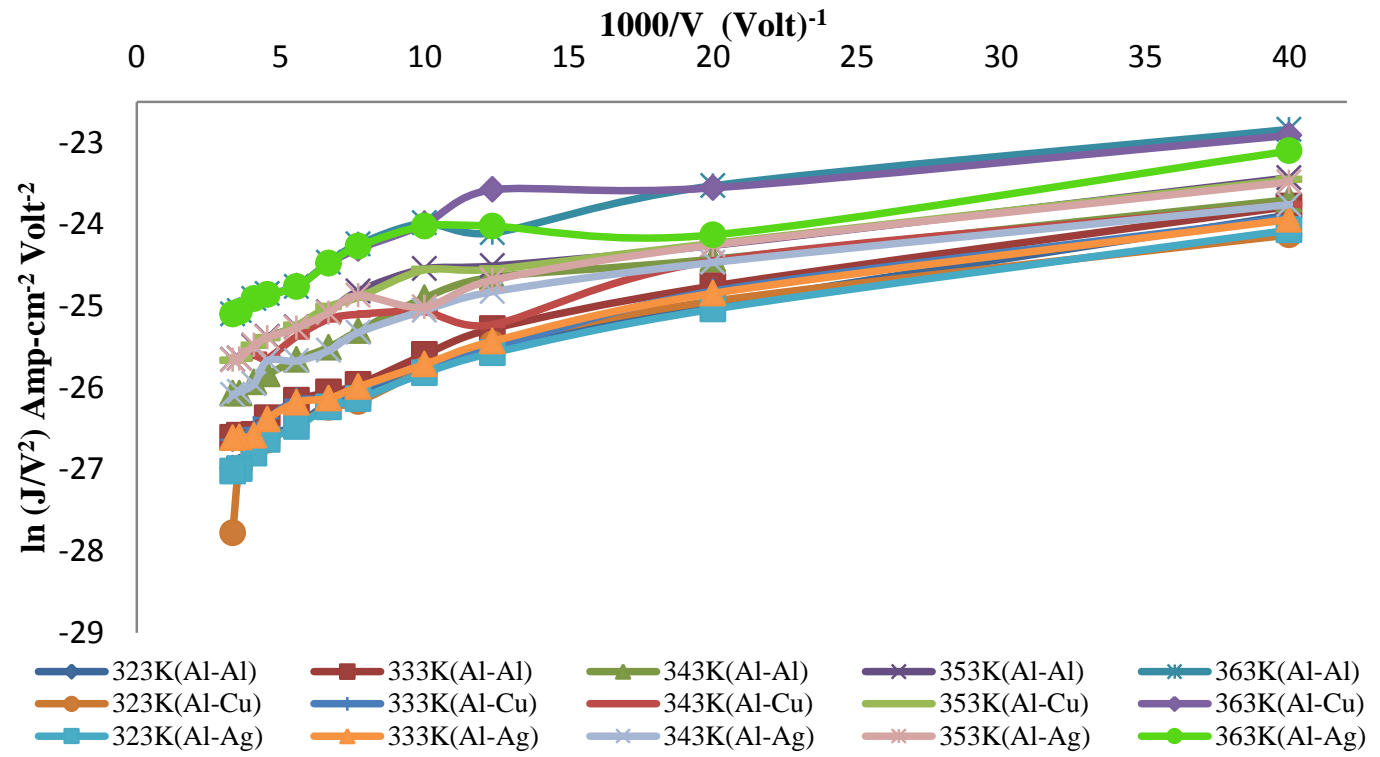

Figure 12. Fowler-Nordheim plots (PVC: PMMA; 8:2) (Al-Al; $\mathrm{Al}-\mathrm{Ag}$; $\mathrm{Al}-\mathrm{Cu}$ electrode combinations)

According to equation(2) Fowler-Nordheim mechanism, characterized by the $\ln \left(\mathrm{J} / \mathrm{V}^{2}\right)$ vs $1000 / \mathrm{V}$ is expected to be a line relation with a negative slope. In the present case the Fowler-Nordheim plots are nearly straight lines with a positive slope for higher as well as lower values of $\mathrm{V}$, indicating the absence of tunneling current as suggested by F-N relation.

\subsection{Schottky plots}

The Schottky Richardson relation for current density $(\mathbf{J})$ and electric field(E) is expressed as,

$$
\mathrm{J}=\mathrm{AT}^{2} \exp \left(\frac{-\mathrm{e}\left(\varnothing-\beta_{\mathrm{SR}} \mathrm{E}^{1 / 2}\right.}{\mathrm{KT}}\right)
$$

Where, $\beta_{\mathrm{SR}}=\left(\frac{\mathrm{e}}{4 \pi \varepsilon_{\mathrm{r}} \varepsilon_{0}}\right)^{1 / 2}$ and $\emptyset=$ work function

and hence from equation(3) $\ln J$ vs $E^{1 / 2}$ plots should be a straight line with a positive slope. [8, 9] 


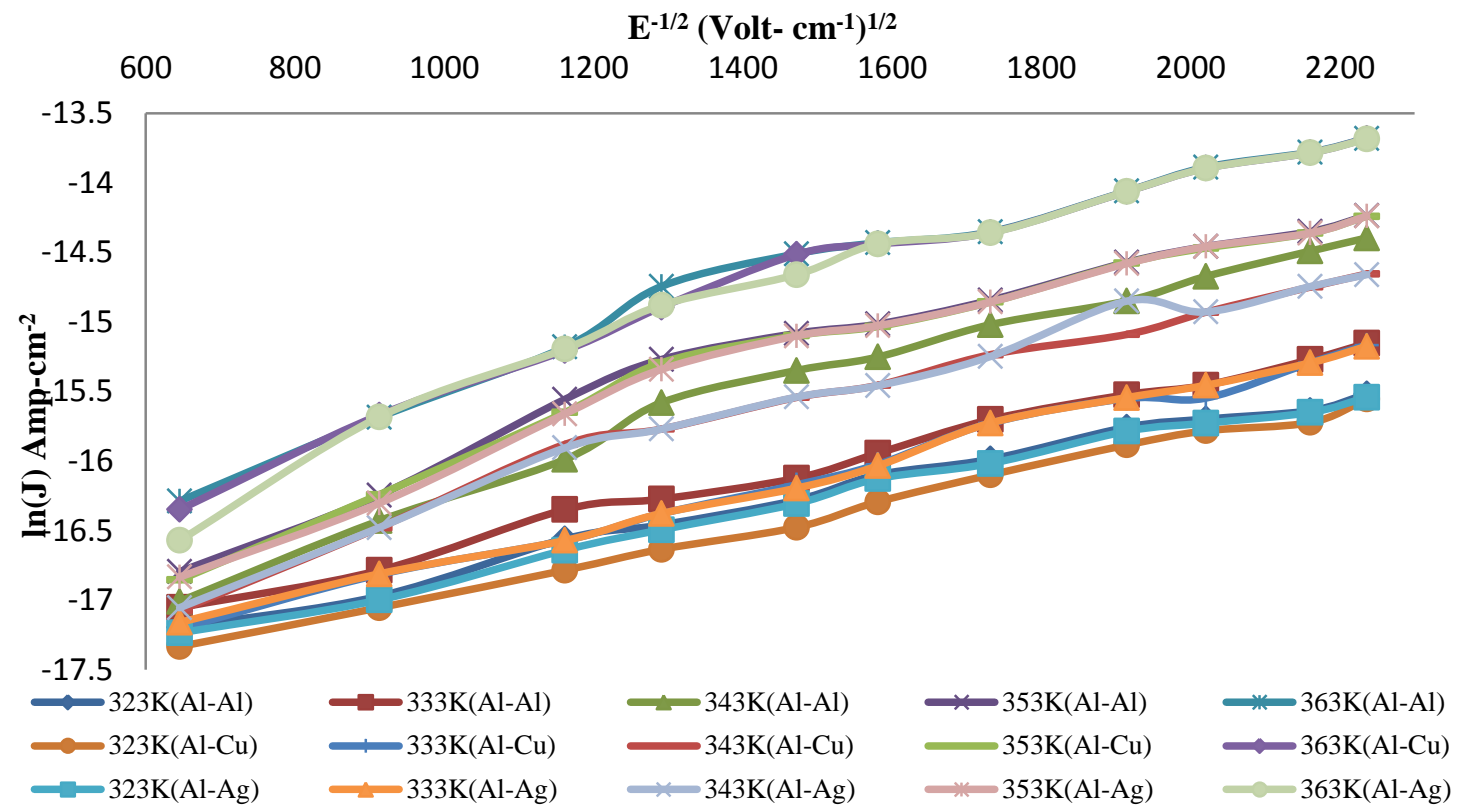

Figure 13. Schottky plots (PVC: PMMA; 5:5) (Al-Al; Al-Ag; Al-Cu electrode combinations)

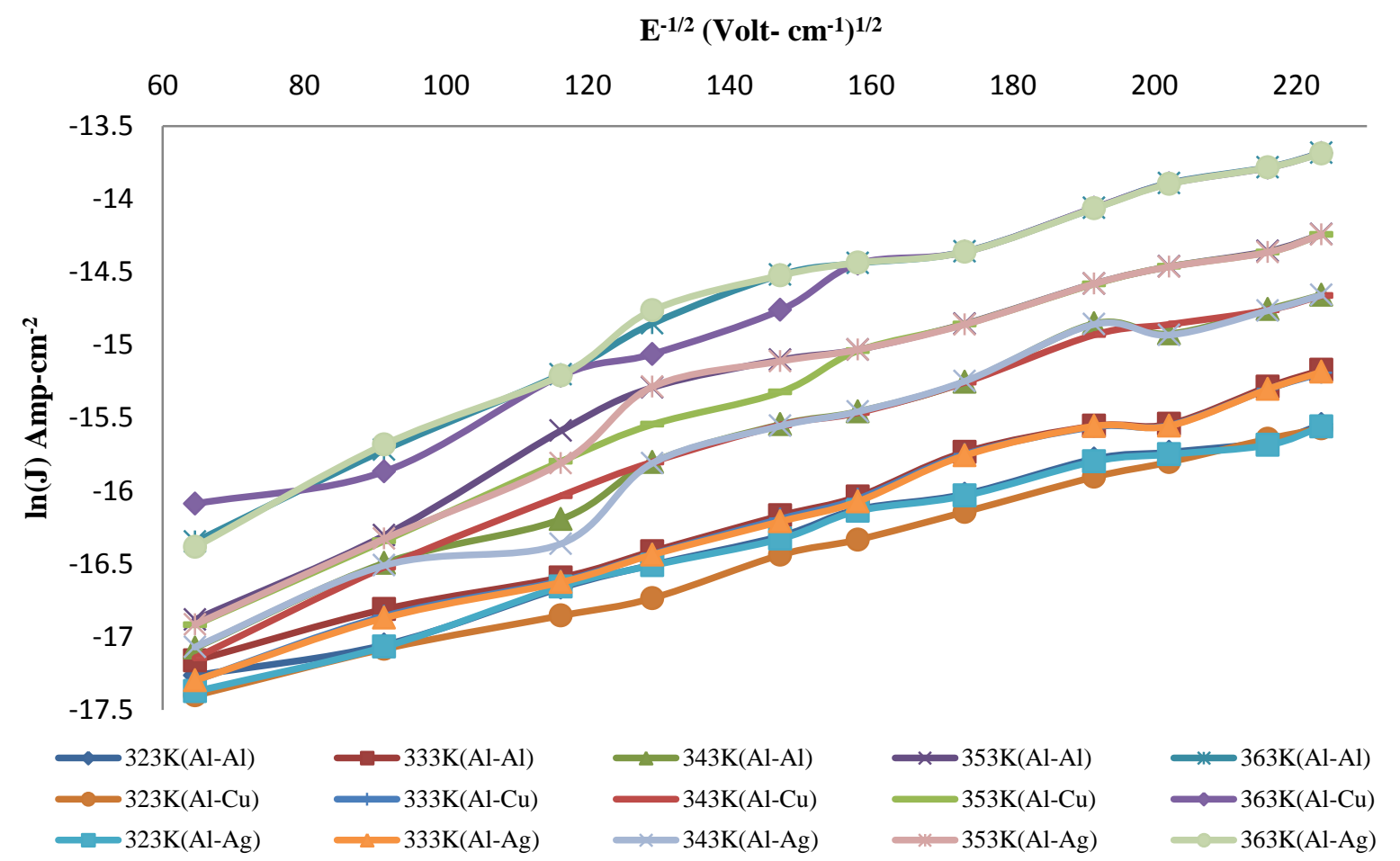

Figure 5. Schottky plots (PVC: PMMA; 6:4) (Al-Al; Al-Ag; Al-Cu electrode combinations) 


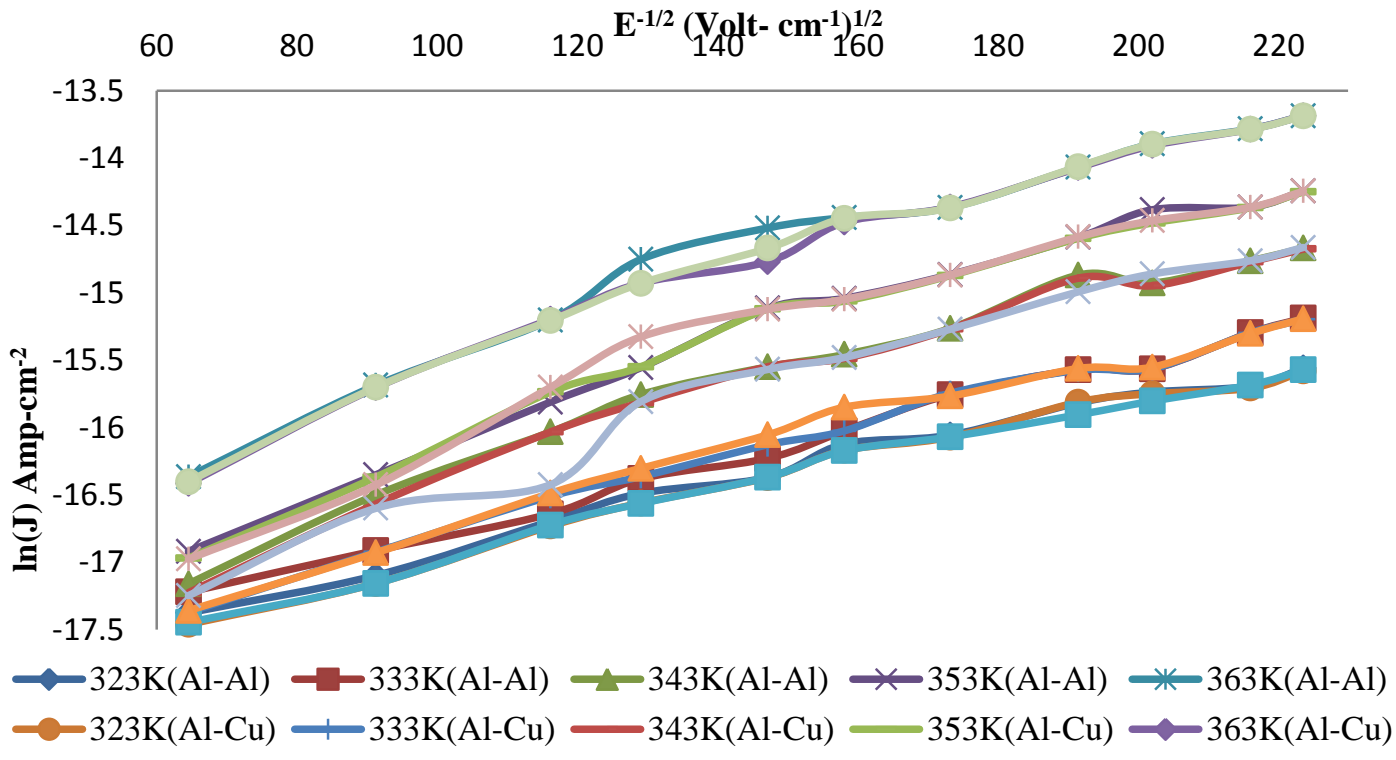

Figure 6. Schottky plots (PVC: PMMA; 7:3) (Al-Al; Al-Ag; Al-Cu electrode combinations)

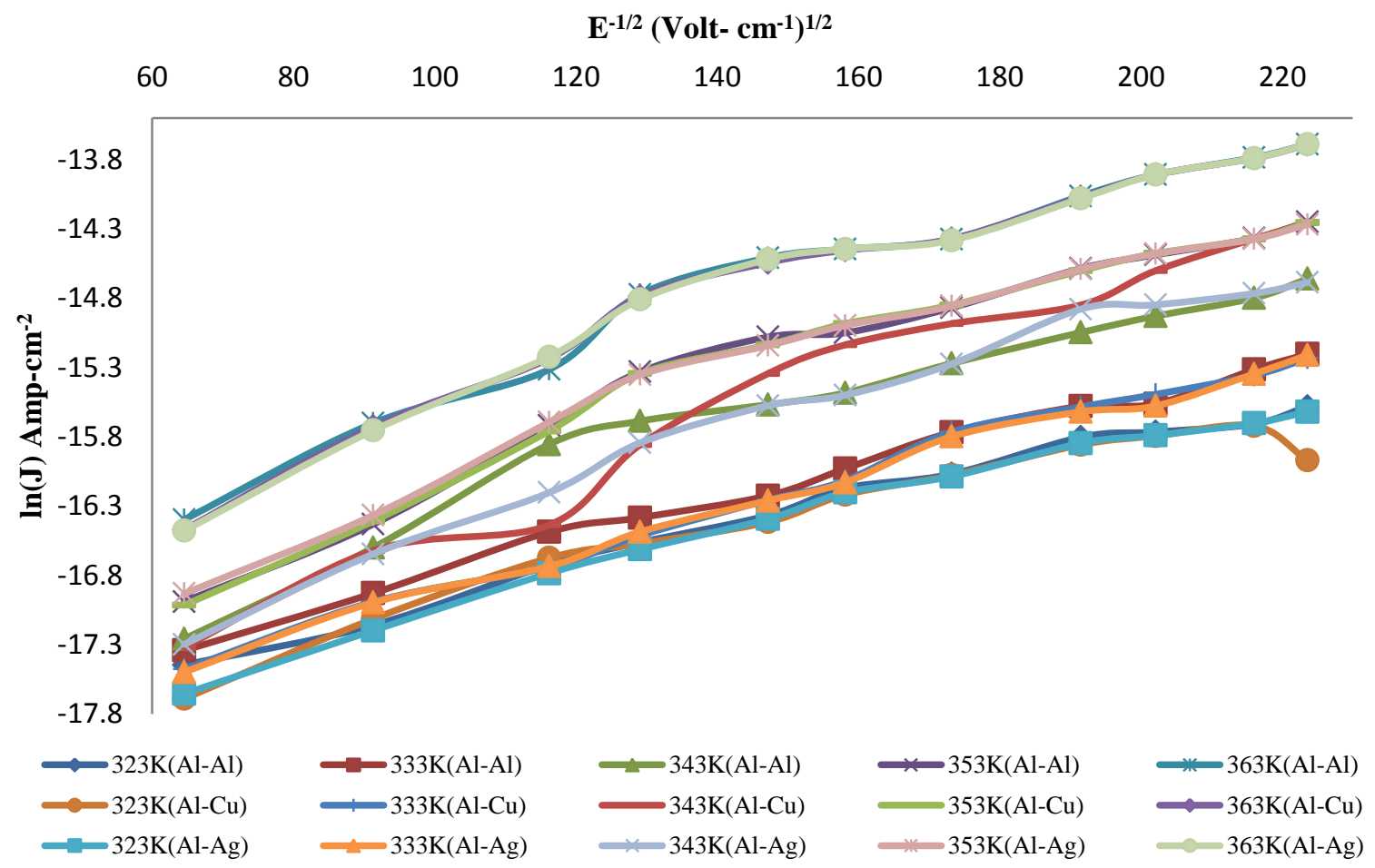

Figure 7. Schottky plots (PVC: PMMA; 8:2) (Al-Al; Al-Ag; Al-Cu electrode combinations)

From Fig.13 to Fig.16 lnJ vs $E^{1 / 2}$ plots observed are found nearly straight line with positive slope. Hence, indicating the applicability of Schottky-Richardson mechanism. Further in the case of SchottkyRichardson mechanism, the current has strong temperature dependence but not in case of P-F mechanisms. The study of temperature dependence of current density, is therefore of great importance. 


\subsection{Current density vs. temperature plots}

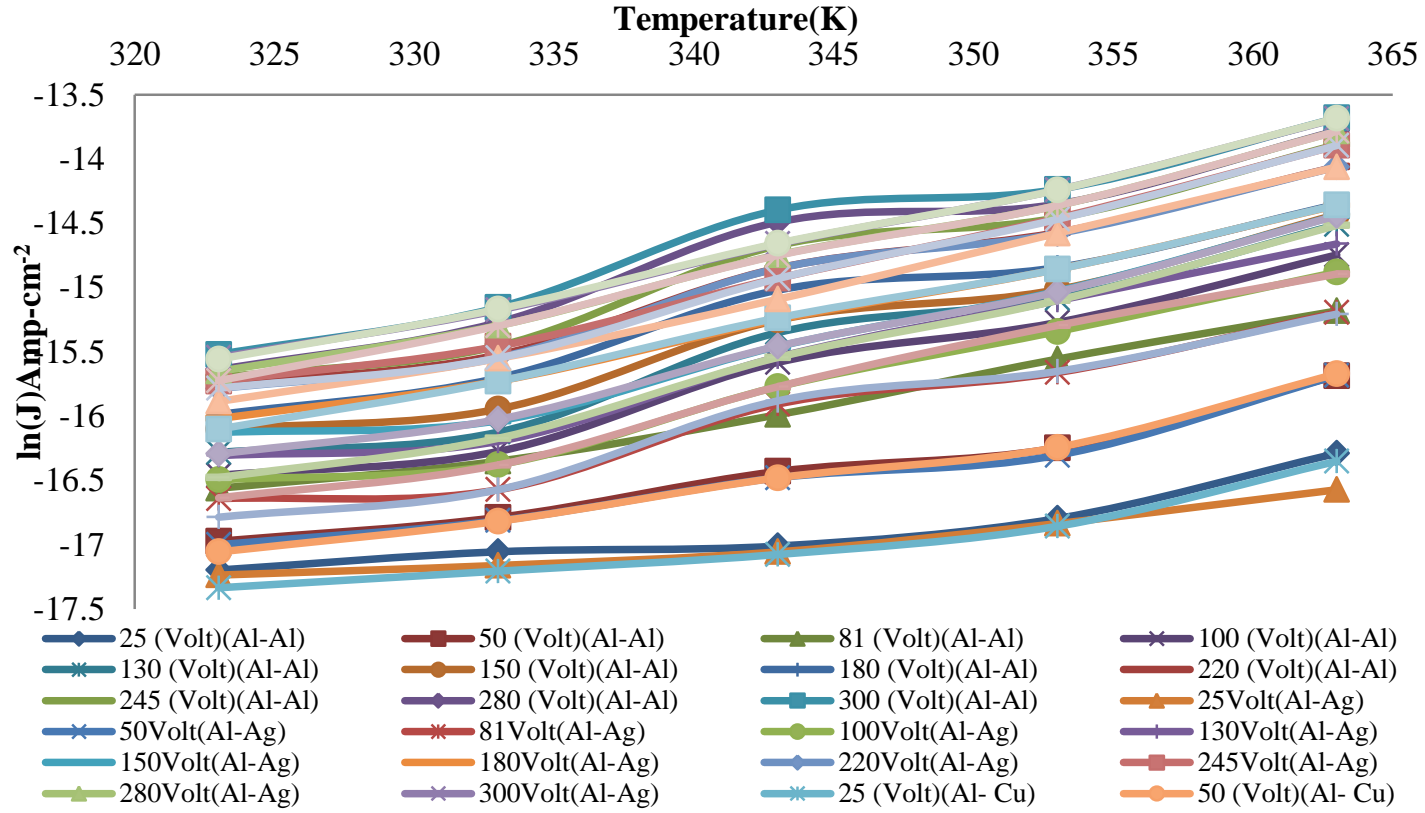

Figure 17. $\mathrm{lnJ}$ vs. temperature plots (PVC: PMMA; 5:5) (Al-Al; $\mathrm{Al}-\mathrm{Ag} ; \mathrm{Al}-\mathrm{Cu}$ electrode combinations)

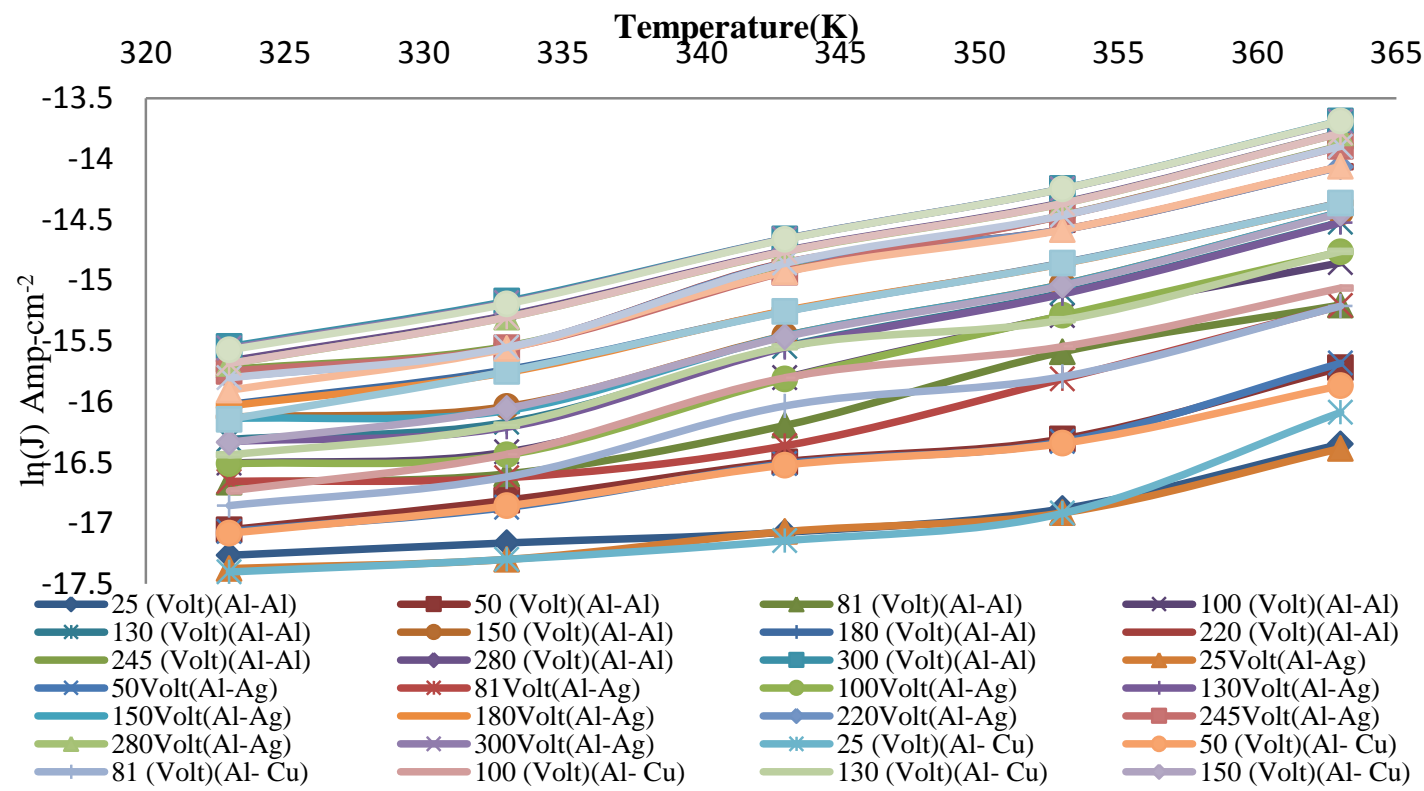

Figure 18. lnJ vs. temperature plots (PVC: $\mathrm{PMMA} ; 6: 4)(\mathrm{Al}-\mathrm{Al} ; \mathrm{Al}-\mathrm{Ag} ; \mathrm{Al}-\mathrm{Cu}$ electrode combinations) 


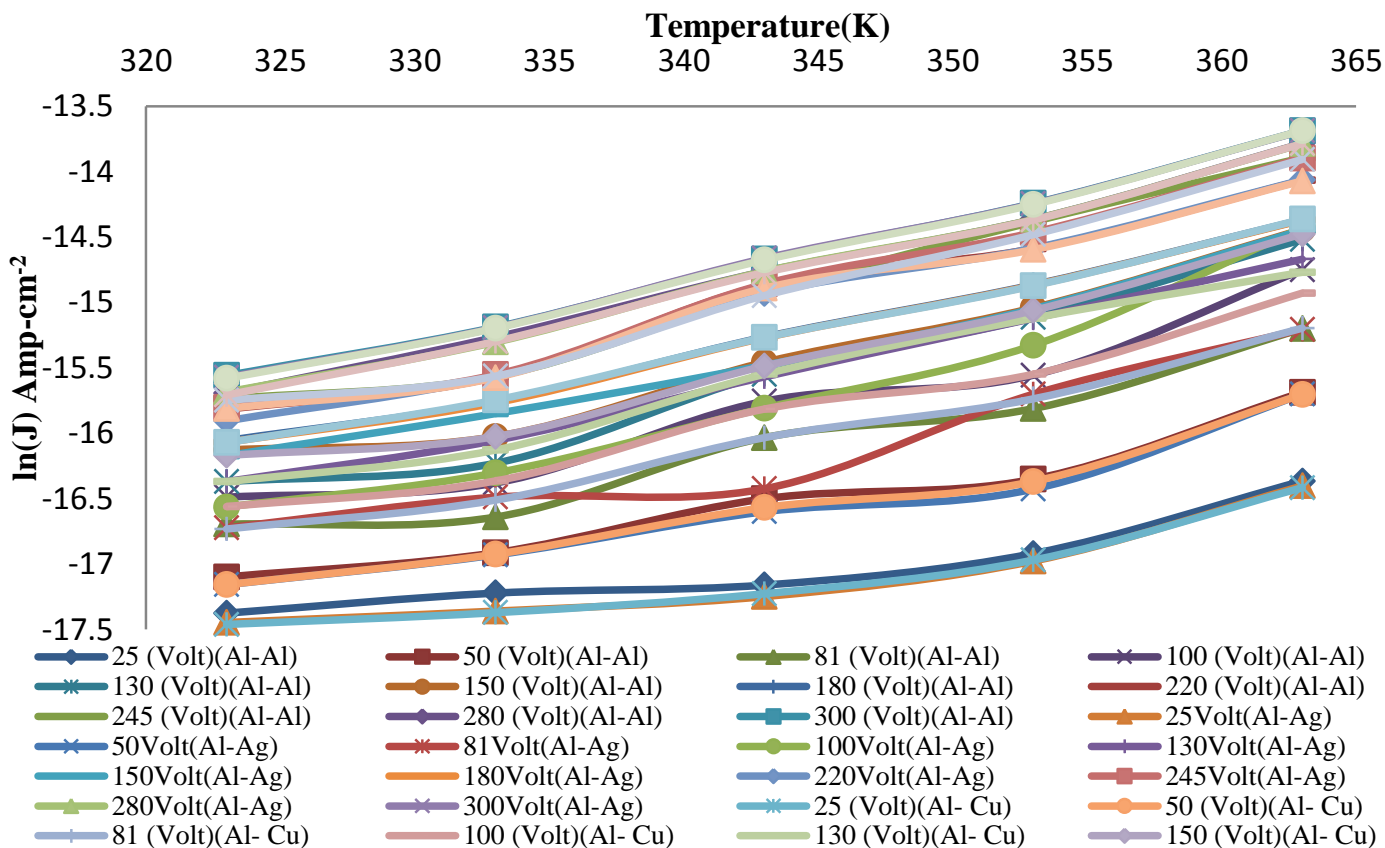

Figure 19. Current density vs. temperature plots (PVC: PMMA; 7:3) (Al-Al; Al-Ag; Al-Cu electrode combinations)

Temperature(K)

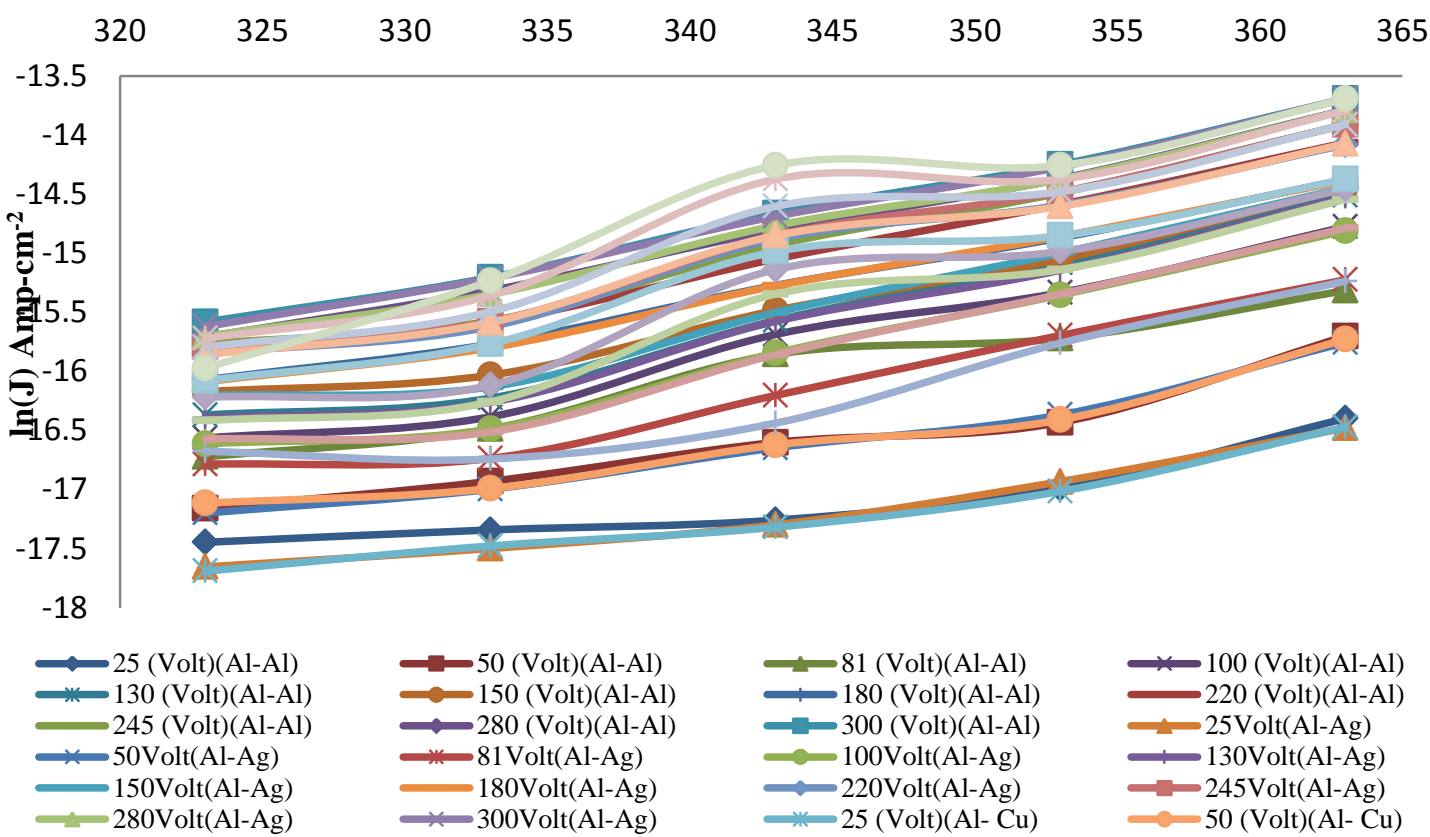

Figure 8. InJ vs. temperature plots (PVC: PMMA; 8:2) (Al-Al; Al-Ag; $\mathrm{Al}-\mathrm{Cu}$ electrode combinations)

From Fig.17 to Fig.20, lnJ linearly increases with temperature. This is an agreement to S-R mechanism.

\subsection{Richardson plots}

The current density for thermionic emission over a potential barrier $\emptyset$, is given by Richardson's law, $\mathbf{J}=\mathrm{AT}^{2} \exp \left(\frac{-\varnothing}{\mathrm{KT}}\right)$ (4) Where, A is the effective Richardson constant.

From (4) it is clear that the graph between $\operatorname{lnJ} / \mathrm{T}^{2}$ vs. $1 / \mathrm{KT}$ from this relation should be a straight line with a negative slope. 


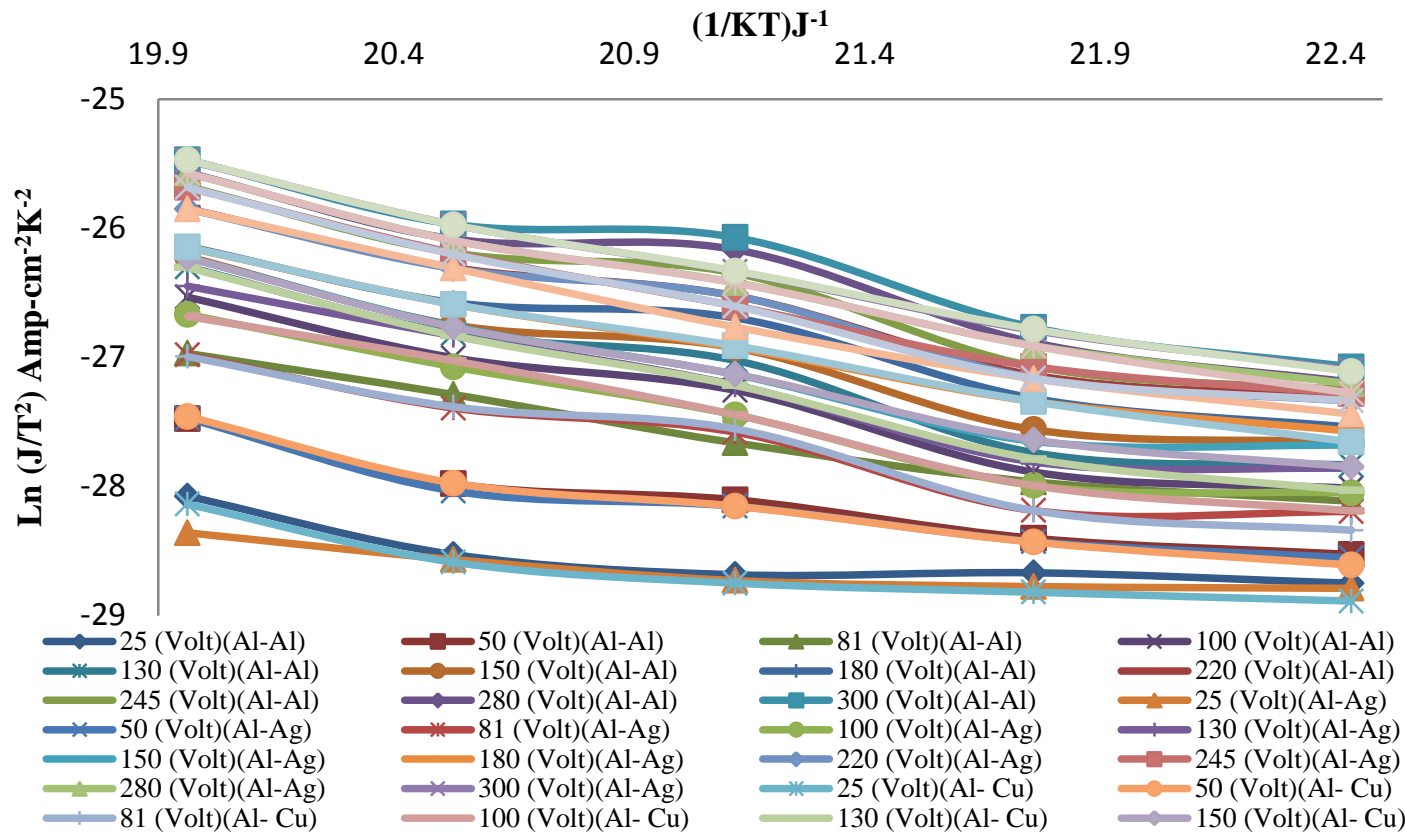

Figure 21. Richardson plots (PVC: PMMA; 5:5) (Al-Al; Al-Ag; $\mathrm{Al}-\mathrm{Cu}$ electrode combinations)

$(1 / K T) J^{-1}$

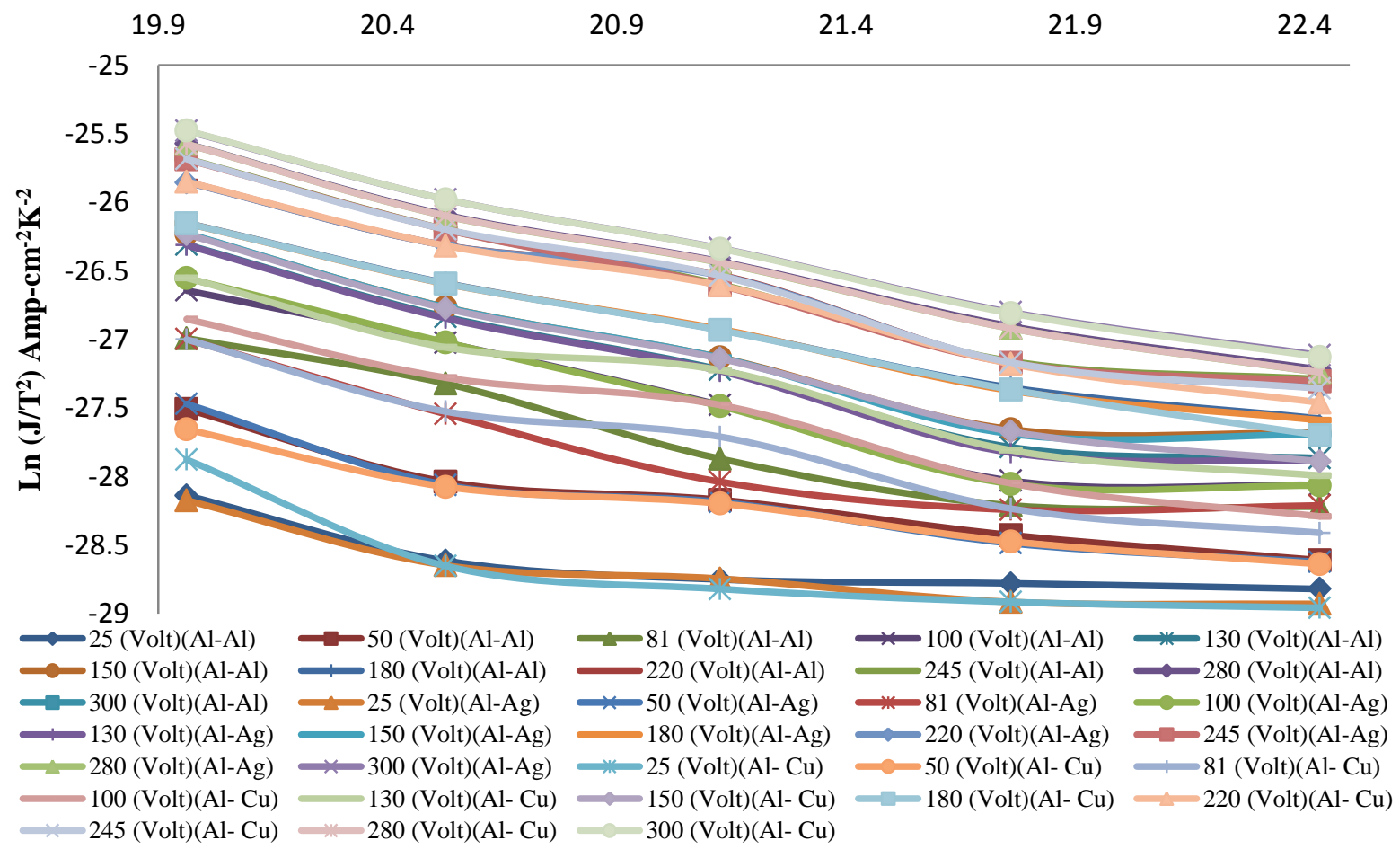

Figure 22. Richardson plots (PVC: PMMA; 6:4) (Al-Al; $\mathrm{Al}-\mathrm{Ag} ; \mathrm{Al}-\mathrm{Cu}$ electrode combinations) 


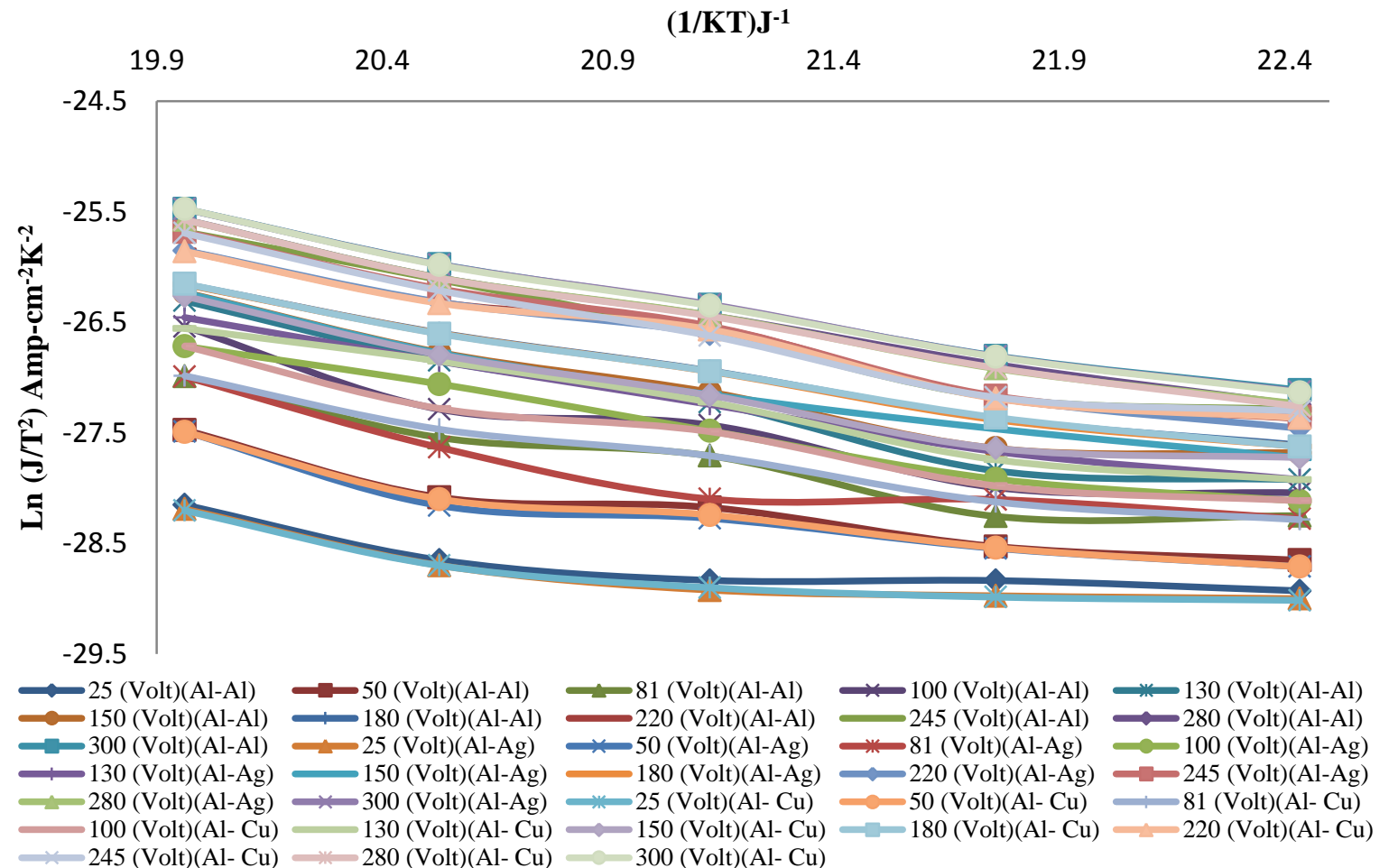

Figure 9. Richardson plots (PVC: PMMA; 7:3) (Al-Al; $\mathrm{Al}-\mathrm{Ag}$; $\mathrm{Al}-\mathrm{Cu}$ electrode combinations)

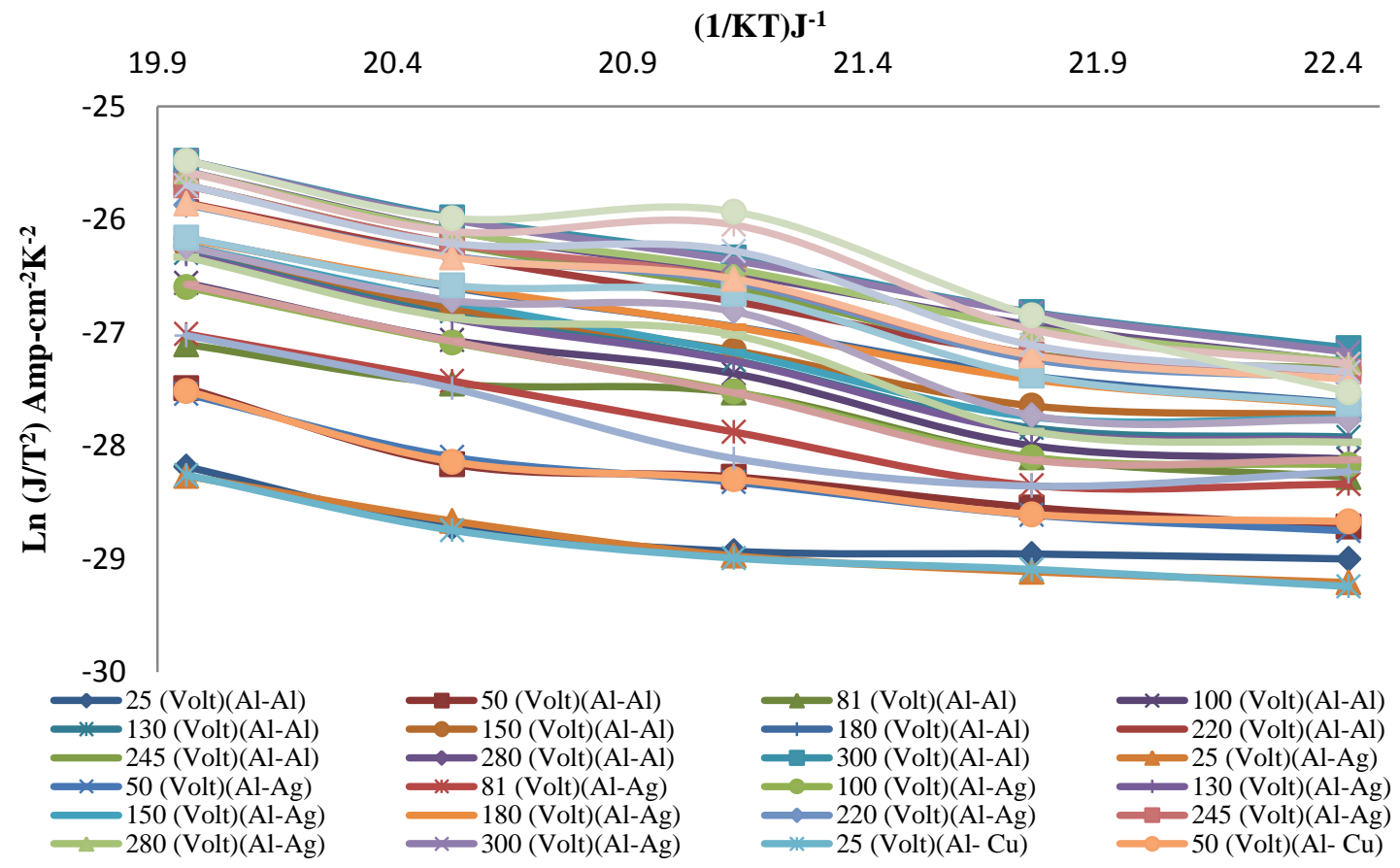

Figure 24. Richardson plots (PVC: PMMA; 8:2) (Al-Al; $\mathrm{Al}-\mathrm{Ag}$; $\mathrm{Al}-\mathrm{Cu}$ electrode combinations)

The plots from Fig.21 to Fig.24 between $\ln \left(\mathrm{J} / \mathrm{T}^{2}\right)$ vs $1 / \mathrm{KT}$ are straight lines with a negative slope referred to as Richardson plots and S-R mechanism requires linearity of these plots in this way the plots observed supports S-R mechanism.

In case of P-F mechanism, the current is due to thermal excitation of trapped electrons via field assisted lowering of trap depth. While Schottky model is due to thermal activation of electrons over metal insulator interface barrier with edit effect of applied field reducing barrier height also in former electrons are liberated from traps while in the later electron emission take place from cathode. Further no strong temperature dependence is observed in former while the later shows strong temperature dependence. 
F-N mechanism characterizes tunneling currents. In the light of comparative characteristic features of different mechanisms of conduction and the observed behavior of the sample, it can be specify concluded that it is $\mathrm{S}-\mathrm{R}$ mechanism that operating in present study.

In ln I vs. In V curves for various type of electrode systems, most of the curves show non Ohmic behavior at higher fields, at sufficiently higher field the conduction current is mainly due to injected space charge,this is further confirm by the value of slope in higher field region.

In order to confirm R-S mechanism, Jonscher and Ansari method of different electrodes is adopted. In this method, the effect of different electrode material viz. $\mathrm{Al}, \mathrm{Cu}$ and $\mathrm{Ag}$ having different work functions 3.38, 4.46, $4.31 \mathrm{eV}$, respectively, on the $\ln \mathrm{I} \mathrm{Vs} \ln \mathrm{V}$ characteristics has to be considered for deciding conduction mechanism. The conduction current through the sample differs when the upper electrode $\mathrm{Al}$ is replaced by $\mathrm{Cu}$ and Ag. The magnitude of current has been found to be higher in similar electrode Al-Al then in dissimilar electrode combination. This shows the effect of the material of the electrodes on the conduction current of the sample sandwiched between them. The values of conduction current seem to be controlled by the effective work function for metal- insulator- metal interfaces. The difference between work function metal 1 and metal 2 will control the magnitude of current but for similar electrode, the characteristics of polymer may prevail as the net contribution of current from charge injected from electrode would then be zero. The work function of the polymer must be taken to lie above those metals. So the resultant barrier height between polymer-metal is sufficiently higher. Their difference will control the magnitude of conduction current. Separate distinct lines are obtained for dissimilar electrode combination. These observations are consistent with the proposed R-S mechanisms and suggest that in higher field regions the conduction is governed by R-S effect in which carriers are injected over the field dependent polymer electrode interfacial barrier.[3, 4, 8, 10,11, 12,]

\section{Conclusions}

After studying electrical conduction through polymer blend under various existing mechanisms, it is observed that in the present case, the behavior cannot be described by P-F and F-N but can be closely described by Schottky and Rechardson mechanisms. This is also evident from the effect of electrode material.

\section{References}

[1] E.J. Carter, F.L. Gardiner, Polymer electronics-a flexible technology, (iSmithers Rapra publishing 2009).

[2] S.H. Deshmukh, D.K. Burghate, V.P. Akhare, V.S. Deogaonkar, P.T. Deshmukh and M.S. Deshmukh, Electrical conductivity of polyaniline doped PVC-PMMA polymer blends, Bull. Mater. Sci. 30(1), Feb 2007, 51-56.

[3] Vijaya S. Sangawar and Neeraja A. Moharil, Study of Electrical, thermal and optical behavior of Polypyrrole filled PVC:PMMA thin film thermo electret, Chem. Sci. Trans. 1(2), 2012, 447-445.

[4] Dr. Y.K. Kulshrestha,Study of charge and emergy transfer mechanism in mixed crystals(thin films )of organic compounds. Ph.D. Thesis, University of Sagar,India, 1980.

[5] A. Servini, A.K. Jonscher, Electrical conduction in evaporated silicon oxide films, Thin Solid Films, Elsevier, (3), 1969, $341-365$.

[6] R.S. Gulalkari, Y.G. Bakale, D.K. Burghate and V.S. Deogaonkar, Electrical conduction mechanism of polyvinyl chloride (PVC)polymethyl methacrylate (PMMA) blend film, PRAMANA-Joural of Physics, 69(3) Sept 2007, 485-490.

[7] J.Frenkel, On pre-breakdown phenomena in insulators and electronic semi conductors, Phys. Rev. 54, $1938,647$.

[8] Gorur G.Raju, Dielectrics in electric fields, 7(Marcel Dekker Inc., New York ISBN: 0-8247-0864-4), 329- 360.

[9] W.Z. Schottky, Schottky efect J.Phys. 14, 1923, 63-74

[10] Ashutosh Verma, P.K. Khare and Rudra Kant Shrivastava,electrode effect on electrical conduction in thin film of polyvinyl pyrrolidone, Indian Journal of Pure and Applied Physics,47, October 2009, 737-744

[11] D.K. Das-Gupta, Molecular process in polymer electrets. J. Electrostatics ,2001, 51-52, 159-166.

[12] G.M. Sesseler, Electret,(Springer- Verlag Berlin Heidelberg New York ,1980) 